\title{
Colorectal Polyps: A Clinical, Endoscopic and Pathologic Study in Iranian Children
}

\author{
Mohammad Taghi Haghi Ashtiani $^{\mathrm{a}}$ Maryam Monajemzadeh ${ }^{\mathrm{a}}$ \\ Farzaneh Motamed $^{\mathrm{b}}$ Hedieh Moradi Tabriz $^{\mathrm{a}}$ Fatemeh Mahjoub $^{\mathrm{a}}$ \\ Hamid Karamian $^{a}$ Mehri Najafi Sani $^{b}$ Gholam Reza Khatami ${ }^{b}$ \\ Ahmad Khodadad $^{\text {b }}$ Fatemeh Farahmand $^{\text {b }}$ Gholam Hossein Fallahi ${ }^{b}$
}

Departments of a Pathology and bediatric Gastroenterology, Children's Medical Center Hospital, Medical Sciences, University of Tehran, Tehran, Iran

\author{
Key Words \\ Colorectal polyps $\cdot$ Children $\cdot$ Colonoscopy $\cdot$ \\ Histopathology
}

\begin{abstract}
Objective: To study the clinical presentation, histology and colonoscopic features of lower gastrointestinal polyps in Iranian children. Material and Methods: Medical reports of children with colorectal polyps were retrospectively reviewed from 1996 to 2005 at the Children's Medical Center Hospital, Iran. A total of 563 cases were studied. Data related to age, sex, family history, signs and symptoms, the size, location, polyp types and associated lesions were collected and analyzed. Results: The mean age of children was $5.66 \pm$ 2.88 years (range 2 months to 17 years), with a male-to-female ratio of 1.61:1.0. The highest incidence was between ages 2 and 10 years (85.1\%). Rectal bleeding was the presenting symptom in $78.5 \%$ cases. The polyps were solitary in $94 \%$ of cases. A majority of polyps (86.3\%) were juvenile and $86.7 \%$ located in the rectosigmoid area. Three percent of cases had a positive family history. One case of Turcot syndrome was also identified. Conclusion: Juvenile polyps remain the most common polyps in Iranian children. Although the presence of a solitary polyp in the rectosigmoid colon is
\end{abstract}

more prevalent, in a significant number of cases they are multiple and located in proximal parts. Polyps must be removed even when asymptomatic because of their probable neoplastic potential.

Copyright $\odot 2008$ S. Karger AG, Basel

\section{Introduction}

Gastrointestinal (GI) polyps are defined as grossly visible protrusions from the mucosal surface. Most polyps are asymptomatic and remain unrecognized, but in symptomatic cases, the major clinical presentations are GI bleeding, abdominal pain, intestinal obstruction and rectal prolapse [1].

Polyps may be classified histologically as neoplastic (benign or malignant) and non-neoplastic (inflammatory or hamartomatous) types $[1,2]$. In pediatrics, colorectal polyps are one of the most important and frequent GI tract conditions, commonly present as painless rectal bleeding and secondary anemia. Most polyps are solitary with no genetic predisposition or long-term risk of neoplasia. Over $90 \%$ of colorectal polyps in children are juvenile polyps, solitary, and located in the rectosigmoid colon and as such, a simple sigmoidoscopy with polypec- 
Table 1. Frequency of different polyps in various age groups

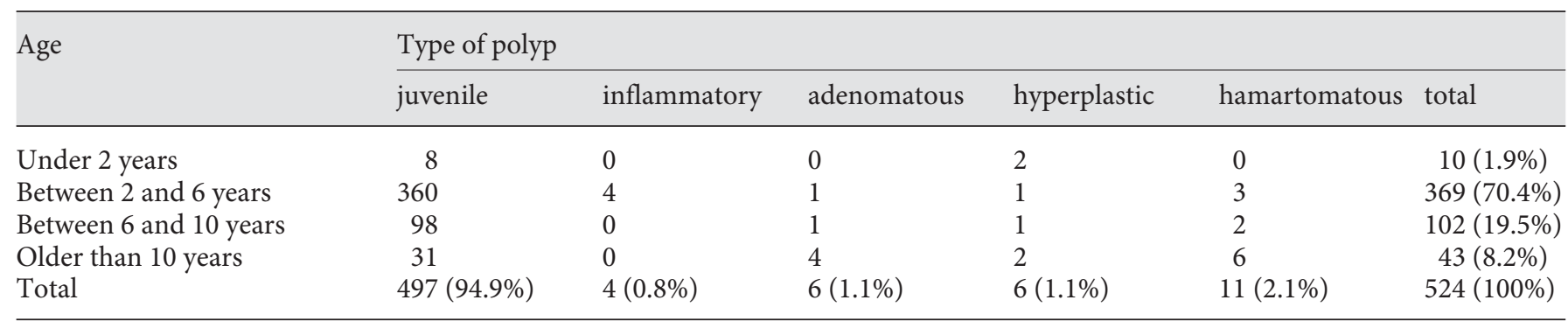

tomy may be sufficient treatment [3-6]. Also, multiple, recurrent or adenomatous polyps must be noted on occasion. Such children require careful attention and periodic monitoring for neoplastic development in the GI tract or other organ systems [7]. Therefore, because of the variety of types and significance of GI polyps, endoscopic examinations and histopathologic evaluations are needed for definitive diagnosis and management of pediatric polyps. Since there are no published studies on juvenile polyps in Iranian children, this study retrospectively evaluated colorectal polyps in a cohort of children in order to determine the frequency, major symptoms and predominant location of these polyps and highlight any racial differences using a sizable number of patients.

\section{Materials and Methods}

Medical reports of children who underwent colonoscopy were examined retrospectively. Total colonoscopy was done from 1996 to 2005 for cases with GI bleeding or conditions in which visualization of colon mucosa was necessary except for rare cases with poor preparation. Polypectomy was done at the Children's Medical Center Hospital (CMCH), Iran. In addition to being a referral tertiary care center, $\mathrm{CMCH}$ is the major teaching hospitals of Tehran University of Medical Sciences. It admits patients from all regions of Iran. Thus it represents a wide spectrum of patients from different socioeconomic levels.

The data related to age, sex, family history, signs and symptoms, size, location, polyp types and associated lesions were collected and analyzed with SPSS 10 software.

\section{Results}

During the study period of 10 years, 1,806 colonoscopies were performed at $\mathrm{CMCH}$, and polypectomy was performed in 563 children (mean age $5.66 \pm 2.88$ years, range 2 months to 17 years). Information on age was not available in $9(1.6 \%)$ cases. The overall male-to-female ratio of the remaining 554 cases was 1.61:1.0. However, for children below 6 years it was 1.7 while that for children older than 6 years was 1.4.

Of the 563 cases, 30 showed pathologic features other than polyps (such as ulcerative colitis, necrotic materials, digested food, lymphoid or granulation tissue and blood clot) and they were excluded from the study; only 533 cases were true polyps histologically.

Among the 524 cases with documented true polyps (both gross and histologically identified), 10 (1.9\%) were under 2 years old, 369 (70.4\%) 2-6 years, 102 (19.5\%) 6-10 years and $43(8.2 \%) 10$ years and over (table 1$)$.

Juvenile polyps were found in all age groups while hyperplastic and adenomatous polyps were more prevalent in those above 10 years of age (table 1). Lower GI bleeding was seen in 523 cases $(98.2 \%$ ) and rectal prolapse was observed in 7 cases (1.3\%), these being the two most common presentations. Rare symptoms included chronic constipation and abdominal pain. The most common presentation of juvenile polyps was rectal bleeding, while other polyps were mainly accompanied with symptoms other than bleeding.

The polyps were located in the rectosigmoid region ( $\mathrm{n}=409,76.7 \%)$ and the colon $(\mathrm{n}=100,18.8 \%)$, and further $24(4.5 \%)$ were noted as spontaneous expulsions during defecation. There was no significant difference in the sexes regarding the location of the polyps.

Data about the size of the polyps were missing in 16 cases. In the remaining 517 cases mean diameter size was $1.22 \pm 0.77 \mathrm{~cm}$ (range $0.1-5 \mathrm{~cm}$ ).

Excluding 9 patients (1.7\%) whose information about the number of polyps was missing in medical reports, a majority ( $\mathrm{n}=499$ patients, $93.6 \%$ ) had a single polyp, 25 (4.7\%) had multiple polyps and only 2 patients from the latter group had more than 5 . 
The most commonly associated lesion found during colonoscopy examination (in order of frequency) were lymphoid hyperplasia and rectal nodularity, solitary colon ulcer, rectal edema and rectal prolapse.

Seventeen cases $(3 \%, 11$ males and 6 females) had a positive family history of colon polyps. Their histopathologic subtypes consisted of juvenile polyps ( 9 cases), hamartomatous polyps (6 cases) and adenoma ( 2 cases). One patient was found to have Turcot syndrome with no positive family history.

\section{Discussion}

In pediatrics, juvenile polyps are the most common tumors in the GI tract; these polyps are usually solitary and most commonly located in the rectosigmoid colon [3-6], similar to our findings in Iranian children.

Mean age and sex distribution of our patients were also similar to those reported in other studies; the majority of them were less than 6 years old and were male [1015]. Lower GI bleeding was the most common presentation in our study, as in most others $[11,12,16,17]$.

Latt et al. [8] and Roth et al. [18] demonstrated that $53-58 \%$ of polyps were multiple and $30-60 \%$ of them were located proximal to the sigmoid colon. In contrast, this study showed that only $6 \%$ of patients had more than one polyp and $18.8 \%$ of polyps were in proximal parts of the colon. This difference might be related to the lower number of cases studied in previous studies.

However, a significant number of patients had polyps proximal to the sigmoid colon, which indicates the imperative need for performing a total colonoscopy in symptomatic children, which is in agreement with other studies [16, 19-21].
According to Jass et al. [19], adenomatous transformation of juvenile polyposis occurs in up to $47 \%$. In our study, we found adenomatous transformation in only $3 \%$ (17 cases) of polyposis; however, serial colonoscopy was considered mandatory for early detection of cancer.

Although a number of studies of pediatric GI polyps were reported from Asia including India [10], Taiwan [12] and Pakistan [13], we conducted this study in Iranian children to highlight any racial differences using a sizable number of patients; however, no racial differences were observed in frequency of different types of polyps.

We found that most polyps in Iranian children present with lower GI bleeding in the age range 2-10 years, are juvenile, single and locate in the rectosigmoid colon. However, a significant number (18.8\%) are located in the proximal region and some are multiple (or polyposis), therefore total colonoscopy must be done in all children with rectal bleeding, particularly in those with a family history of polyposis or GI adenocarcinomas.

The limitation of our study was a few missing data in medical records as with any retrospective study, which we hope is not of much overall significance.

\section{Conclusion}

Although the presence of solitary polyps in the rectosigmoid colon is more prevalent, a significant number of cases were multiple and located in proximal parts. This emphasizes the need for total colonoscopy in all symptomatic patients. Polyps must be removed even if asymptomatic because of their probable neoplastic potential.

\section{References}

1 Gonzales-Peralta RP, Anderson JM: Polyps and polyposis syndromes; in Wyllie R (ed): Pediatric Gastrointestinal Disease: Pathophysiology, Diagnosis and Management, ed 2. Philadelphia, Saunders, 1999, pp $443-$ 453.

2 Cooper HS: Intestinal neoplasms; in Sternberg SS (ed): Diagnostic Surgical Pathology, ed 3. Philadelphia, Lippincott Williams \& Wilkins, 1999, pp 1413-1436.

3 Mestre JR: The changing pattern of juvenile polyps. Am J Gastroenterol 1986;81:312314.

Colon Polyps in Children

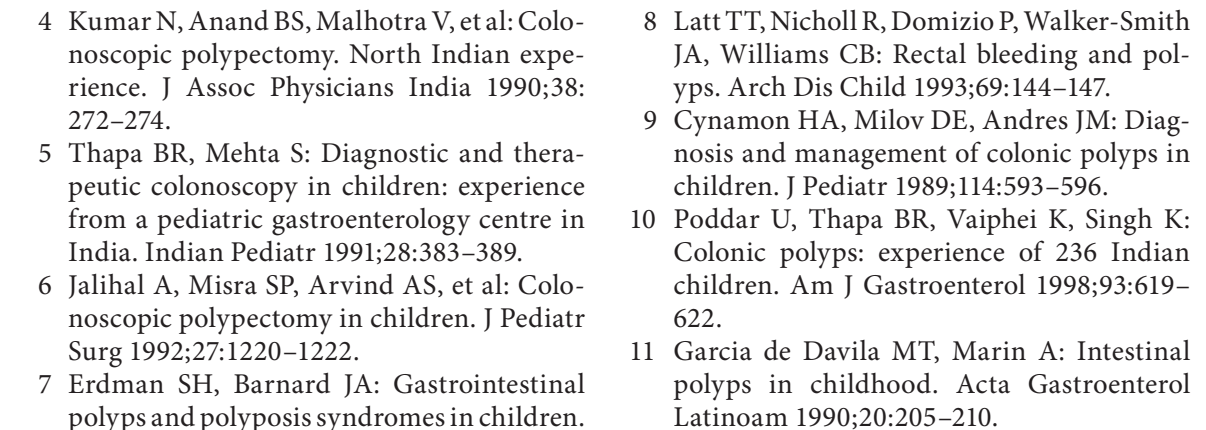
. rience. J Assoc Physicians India 1990;38

Jalihal A, Misra SP, Arvind AS, et al: Colonoscopic polypectomy in children. J Pediatr Erdman SH, Barnard JA: Gastrointestinal Curr Opin Pediatr 2002;14:576-582.

\begin{abstract}
Latinoam 1990;20:205-210.
Latt TT, Nicholl R, Domizio P, Walker-Smith JA, Williams CB: Rectal bleeding and polyps. Arch Dis Child 1993;69:144-147.

Cynamon HA, Milov DE, Andres JM: Diagnosis and management of colonic polyps in children. J Pediatr 1989;114:593-596. children. Am J Gastroenterol 1998;93:619622 . polyps in childhood. Acta Gastroentero
\end{abstract}

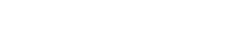


12 Ko Fy, Wu TC, Hwang B: Intestinal polyps in children and adolescents - a review of 103 cases. Zhonghua Min Guo Xiao Er Ke Yi Xue Hui Zhi 1995;36:197-202.

$\checkmark 13$ Mandhan P: Juvenile colorectal polyps in children: experience in Pakistan. Pediatr Surg Int 2004;20:339-342.

14 Jimenez Mesa G, Fragoso Arbelo T: Endoscopic polypectomy of the colon in children. Acta Gastroenterol Latinoam 1985;15:221224 .
15 Huaroto M, Lozano R, Beteta O, Huaman C: Pediatric colonoscopic polypectomy. Rev Gastroenterol Peru 1994;14:204-208.

16 Waitayakul S, Singhavejsakul J, Ukarapol N: Clinical characteristics of colorectal polyp in Thai children: a retrospective study. J Med Assoc Thai 2004;87:41-46.

17 Guitron A, Adalid R, Nares J, Mena G, Gutierrez JA: Colonic polyps in children: experience with polypectomy. Rev Gastroenterol Mex 1999;64:19-22.

18 Roth SI, Helwig EB: Juvenile polyps of the colon and rectum. Cancer 1963;16:468-479.
19 Jass JR, Williams CB, Bussey HJ, et al: Juvenile polyposis - a precancerous condition. Histopathology 1988;13:619-630.

20 Giardiello FM, Hamilton SR, Kern SE, et al: Colorectal neoplasia in juvenile polyposis or juvenile polyps. Arch Dis Child 1991;66:971975.

21 Ukarapol N, Singhavejakul J, Lertprasertsuk $\mathrm{N}$, Wongsawasdi L: Juvenile polyp in Thai children - clinical and colonoscopic presentation. World J Surg 2007;31:395-398. 